\title{
Synthesis of an ordered mesoporous carbon with graphitic characteristics and its application for dye adsorption
}

\author{
Nuran Boke, Ziboneni G. Godongwana and Leslie F. Petrik
}

\begin{abstract}
An ordered mesoporous carbon (OMC) was prepared by a chemical vapor deposition technique using liquid petroleum gas (LPG) as the carbon source. During synthesis, LPG was effectively adsorbed in the ordered mesopores of SBA-15 silica and converted to a graphitic carbon at $800{ }^{\circ} \mathrm{C}$. X-ray diffraction and nitrogen adsorption/desorption data and high-resolution transmission electron microscopy (HRTEM) of the OMC confirmed its ordered mesoporous structure. The OMC was utilized as an adsorbent in the removal of dyes from aqueous solution. A commercial powder activated carbon (AC) was also investigated to obtain comparative data. The efficiency of the OMC for dye adsorption was tested using acidic dye acid orange 8 (AO8) and basic dyes methylene blue (MB) and rhodamine $\mathrm{B}$ (RB). The results show that adsorption was affected by the molecular size of the dye, the textural properties of carbon adsorbent and surface-dye interactions. The adsorption capacities of the OMC for acid orange 8 (AO8), methylene blue (MB) and rhodamine $\mathrm{B}$ (RB) were determined to be 222, 833, and $233 \mathrm{mg} / \mathrm{g}$, respectively. The adsorption capacities of the $\mathrm{AC}$ for $\mathrm{AO}$, $\mathrm{MB}$, and $\mathrm{RB}$ were determined to be 141,313 , and $185 \mathrm{mg} / \mathrm{g}$, respectively. The OMC demonstrated to be an excellent adsorbent for the removal of $\mathrm{MB}$ from wastewater.
\end{abstract}

\section{Introduction}

Large volumes of colored wastewater are generated by both dye manufacturing processes and dye consuming industries such as the textile, leather and paper and plastics industries [1-3]. Two percent of dyes that are produced are directly released into aqueous effluent, and in textile industry, $10 \%$ of the dyes are lost during coloration process [2]. Untreated wastewater can reach and mix with water bodies and have harmful impacts on the environment [4]. Dye concentrations as low as $1 \mathrm{mg} / \mathrm{L}$ imparts color to drinking water [5]. Many dyes may be toxic and even carcinogenic [1]. For the protection of public health and environmental quality, wastewater must be treated before it is returned to the environment for further use.

Several treatment methods have been applied for the removal of dyes from wastewaters, such as sedimentation, filtration, chemical treatment, oxidation, electrochemical methods, advanced oxidation processes, biological treatment, adsorption and ion exchange [6]. Among these methods, adsorption is considered to be an effective and economic method for the elimination of dyes from waste-water [7]. Activated carbon has been widely investigated as an adsorbent in the removal of color originating from different types of dyes such as acid, basic (cationic), disperse, direct, reactive and solvent dyes [6, 8]. Activated carbons usually contain micropores $(0-2 \mathrm{~nm})$, which prohibit the entrance of large molecules, and consequently exhibit low adsorption capacities for large dye molecules [9- 
13]. Mesoporous activated carbons (pore size 2-50 $\mathrm{nm}$ ) have been observed to be suitable for the adsorption of large molecules such as dyes vitamin $B_{12}$ and humic acid $[14,15]$. However, mesoporous activated carbons are composed of both mesopores and micropores, the latter of which cannot be utilized to adsorb large molecules, resulting in the inefficient use of the adsorbent. Recently, researchers have focused much of their attention to the development of new carbon materials with controlled pore sizes to use in applications such as the adsorption and catalytic transformation of large molecules [16]. Ordered mesoporus carbons (OMCs) can be synthesized via a hard template method by using sucrose or furfuryl alcohol as the carbon source and ordered mesoporous silica templates such as three-dimensional cubic MCM-48, KIT-5 [17] and KIT-6 [18] and two-dimensional SBA-15 [17]. The obtained OMCs have very high specific surface areas, regular mesopores, and several shapes such as cubic carbon, carbon nanocage [17], cubic carbons with rodtype or tubular nanostructure [18] and two-dimensional rods [17] according to the template selected.

In the typical synthesis of OMCs, the liquid carbon precursor is impregnated into the pores of the silica template from solution and later carbonized in a two-step procedure, followed by template removal with $\mathrm{NaOH}$ or HF. Although this method yields highly ordered mesoporous carbon materials, as mentioned above, it is not applicable for large scale-up [19]. An alternative method for preparing OMCs is to use chemical vapor deposition (CVD). In this type of preparation, the gaseous carbon precursor easily penetrates the pores of the porous silica template from the vapor phase and simultaneously decomposes to graphitic carbon [20-22].

In the present study, an ordered mesoporous carbon with a graphitic structure was successfully prepared by CVD using SBA-15 as the template and liquid petroleum gas (LPG) as the carbon source. The use of the OMC as an adsorbent in the removal of acid orange 8 (AO8), an acid dye, and methylene blue (MB) and rhodamine B (RB), basic dyes, from aqueous solution was investigated. The objective of this study was to understand the relationship between the textural properties of the OMC and its relative adsorption capacity for dye molecules of various sizes and to utilize the OMC in the removal of dye molecules of various sizes from wastewater. In this study, a commercial powder activated carbon was also used for comparison purposes. To our knowledge, this study represents the first application of a graphitic OMC obtained using the CVD technique for the adsorption of dyes.

\section{Experimental \\ 2.1 Materials}

The dyes used in the experiments were of analytical grade (Sigma): acid orange 8 (AO8) $\left(\mathrm{C}_{17} \mathrm{H}_{14} \mathrm{~N}_{2} \mathrm{O}_{4} \mathrm{~S} . \mathrm{Na}\right)(364.36 \mathrm{~g} / \mathrm{mol}$, purity $65 \%)$, methylene blue $\left(\mathrm{C}_{16} \mathrm{H}_{18} \mathrm{CN}_{3} \mathrm{~S}^{*} \mathrm{xH}_{2} \mathrm{O}\right)$ (319.85 g/mol, purity $95 \%$ ), and $\mathrm{RB}\left(\mathrm{C}_{2} 8 \mathrm{H}_{31} \mathrm{ClN}_{2} \mathrm{O}_{3}\right)(479.02 \mathrm{~g} / \mathrm{mol}$, purity $95 \%)$. Activated carbon and $\mathrm{NaOH}$ were purchased from SaarChem and Kimix, South Africa, respectively. The molecular sizes of $\mathrm{AO}, \mathrm{MB}$ and $\mathrm{RB}$ were calculated using the SPARTAN 08 computational chemistry package, the schematic structure of each dye is shown in Fig. 1 [23].

\subsection{Preparation of SBA-15 and OMC}

SBA-15 was synthesized as follows, with small modifications from the literature [24]. $4.1 \mathrm{~g}$ of Pluronic P123 (Aldrich) was dissolved in an acidic solution of $13.2 \mathrm{~g}$ of $37 \% \mathrm{HCl}$ and 20 $\mathrm{g}$ of $\mathrm{H}_{2} \mathrm{O}$ by mixing, followed by the addition of $10 \mathrm{~g}$ of tetraethylorthosilicate (TEOS)

\section{http://repository.uwc.ac.za}


(Aldrich), and stirred at room temperature for $3 \mathrm{~h}$. The formed gel was transferred to a capped bottle and further stirred at room temperature for 3 days. The resulting mixture was aged at $90 \mathrm{oC}$ for 3 days, filtered and washed with pure water, and dried at room temperature for $24 \mathrm{~h}$. The powder was calcined at $550 \mathrm{oC}$ for $5 \mathrm{~h}$ to remove the organic template, and SBA-15 was obtained. The ordered mesoporous carbon (OMC) was prepared by CVD using SBA-15 as template and liquid petroleum gas (LPG) as the carbon precursor [20].

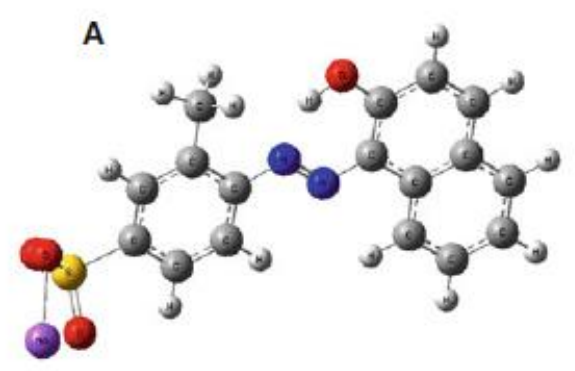

$1.50 * 0.88 * 0.46 \mathrm{~nm}^{3}$

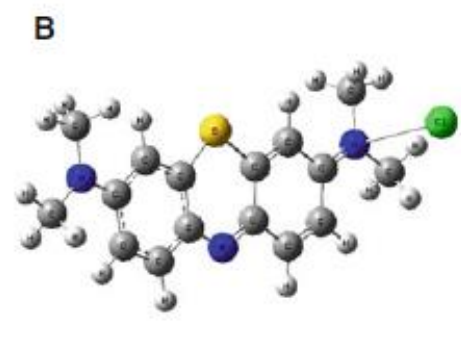

$1.52 * 0.69 * 0.50 \mathrm{~nm}^{3}$

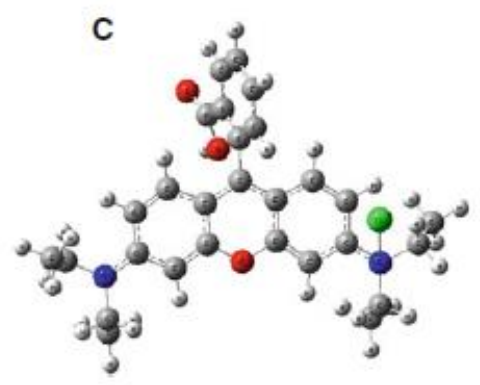

$1.61 * 1.29 * 0.71 \mathrm{~nm}^{3}$

Fig. 1 Molecular structure and estimated size of Acid orange 8 (a), methylene blue (b), Rhodamine B (c) (Color figure online)

To this end, $2 \mathrm{~g}$ of SBA-15 was weighed into a ceramic boat, which was then placed into a tubular furnace. Once appropriately sealed, LPG was flowed at $50.0 \mathrm{~mL} / \mathrm{min}$, and the furnace temperature was ramped to $800 \mathrm{oC}$ at a heating rate of $1.67 \mathrm{oC} / \mathrm{min}$. The sample was carbonized at $800 \mathrm{oC}$ for 105 min (optimum time) under LPG flow. The resulting mesoporous silica/carbon composite was refluxed with $50 \mathrm{~mL}$ of $1.0 \mathrm{M} \mathrm{NaOH}$ at $75 \mathrm{oC}$ for 3 $\mathrm{h}$ to dissolve the silica template. The final product was rinsed with pure water until the $\mathrm{pH}$ was between 7 and 8 , recovered by filtration, and dried at $90 \mathrm{oC}$ for $60 \mathrm{~min}$.

\subsection{Characterization}

The morphological structure of the OMC was observed using FEI scanning electron microscope (FEG-SEM 230). The OMC was viewed on a G2 F2O X Twin Mat $200 \mathrm{kV}$ Tecnai FEG-TEM transmission electron microscope operated at an accelerating voltage of $200 \mathrm{kV}$. The triple subtractive configuration of a Jobin-Yvon T64000 Raman spectrometer with a micro-Raman attachment and the $514.5 \mathrm{~nm}$ line of an argon ion laser were used to measure the Raman spectra of the OMC. The laser diameter used to probe the sample was approximately 1.5 microns, and the power at the sample was $1.22 \mathrm{~mW}$. Low-angle X-ray diffraction (XRD) patterns of SBA-15 and the OMC were recorded using a Bruker AXS Advance D8 diffractometer. The operating voltage and current of the X-ray tube were 40 $\mathrm{kV}$ and $40 \mathrm{~mA}$, respectively. The surface area and porosity of the $\mathrm{OMC}$ and $\mathrm{AC}$ were determined using a Micrometrics TriStar 3000 surface area analyzer by the nitrogen sorption method. Samples were degassed overnight under a nitrogen atmosphere at a temperature of $90 \mathrm{oC}$. Before the analysis, the samples were cooled under a nitrogen atmosphere. Nitrogen adsorption-desorption isotherms were plotted as relative pressure $\left(\mathrm{p} / \mathrm{p}_{\mathrm{o}}\right)$ versus adsorbed gas volume. The pore size distributions and pore volumes were determined from the adsorption part of the isotherm by using the Barrett-Joyner-Halenda (BJH) method. 


\subsection{Adsorption experiments}

Duplicate batch adsorption tests were carried out to determine the AO8, MB, and RB adsorption capacity of OMC and AC. Fifty milliliters of dye solution was contacted with 10 $\mathrm{mg}$ of carbon sample, and the solution was shaken for $24 \mathrm{~h}$ in a mechanical shaker at $25 \mathrm{oC}$ to reach equilibrium. After shaking, the dye solution was separated from the carbon by filtration. The dye concentrations were determined via a spectrophotometric method. The absorbances of AO8, MB, and RB solutions were measured at kmax of 490, 661 and 554 $\mathrm{nm}$, respectively, according to the Beer-Lambert law, on a UV/Visible GBC UV/VIS 920 spectrophotometer. The equilibrium dye adsorption capacity of each adsorbent (Qe) (mg/g) was determined using Eq. 1

$$
\mathrm{Q}_{\mathrm{e}}=\left(\mathrm{C}_{\mathrm{o}}-\mathrm{C}_{\mathrm{e}}\right) * \mathrm{~V} / \mathrm{m}
$$

where $\mathrm{C}_{\mathrm{O}}$ and $\mathrm{C}_{\mathrm{e}}$ are the initial and the equilibrium concentrations of the dye in the aqueous solution $(\mathrm{mg} / \mathrm{L})$, respectively. In this equation $\mathrm{V}$ is the volume of the adsorption solution $(\mathrm{L})$, and $\mathrm{m}$ is the mass of the adsorbent $(\mathrm{g})$.

To investigate the effect of $\mathrm{pH}$ on adsorption the dye solutions at several $\mathrm{pH}$ values were prepared. The adjustment of the $\mathrm{pH}$ of each dye solution to the desired value was done by adding dilute $\mathrm{NaOH}$ or $\mathrm{HCl}$ solution.

\section{Results and discussion}

\subsection{Characterization of the adsorbents}

OMC nanoparticles measured $71 \mathrm{~nm}$ in diameter, as observed by scanning electron microscope (SEM) (Fig. 2a). EDS analysis of the SEM image of the OMC (not given here) showed no $\mathrm{Si}$ remaining from the template, indicating that the silica template was completely removed by etching with $\mathrm{NaOH}$. A transmission electron spectroscopy (TEM) image of the OMC was recorded along the direction perpendicular to the pore axis as shown in Fig. 2b. The EDS spectrum obtained from TEM analysis indicates that the structure of the OMC was composed of mainly carbon and a very small quantity of oxygen. Raman spectroscopy is most sensitive to highly symmetric covalent bonds with little or no natural dipole moment, for instance, carbon-carbon bonds. Thus, Raman spectroscopy is a very valuable tool in the characterization of nano structured carbons. The Raman spectrum of the OMC showed two bands at $1,350 \mathrm{~cm}^{-1}$ (disorder or D band) and $1,588 \mathrm{~cm}^{-1}$ (graphite or $\mathrm{G}$ band), as shown in Fig. 3. Band $\mathrm{G}$ was ascribed to the Raman active $\mathrm{E}_{2 \mathrm{~g}}$ mode of graphite [20]. Band D is related to the structural disorder of graphite. The degree of crystallinity of the $\mathrm{OMC}$ can be estimated by determining the $\mathrm{G}$ band position, the full width at half maximum (FWHM) of the G band, and the intensity ratio between D and $\mathrm{G}$ (ID/IG) [25]. It was reported that, for a series of samples in the poor-to-high-crystallinity range, increasing graphitization was recognized by the shift in the $G$ band from approximately 1,590 to $1,582 \mathrm{~cm}^{-1}$ and the narrowing of its FWHM from 55 to $20 \mathrm{~cm}^{-1}$ until highly crystalline graphite was achieved [25]. The G band's FWHM and the ID/IG of

the $\mathrm{OMC}$ were determined to be $51 \mathrm{~cm}^{-1}$ and 1.05, respectively, from Fig. 3. The ID/IG of the $\mathrm{OMC}$ was out of the range reported for poorly organized carbonaceous material, i.e., between 1.2 and 2.6 [25]. This information was confirmed by HRTEM (shown in Fig. 2b) and selected area electron diffraction analysis (Fig. 2c), indicating that the pore walls of the OMC were highly crystalline.

\section{http://repository.uwc.ac.za}


Figure 4 shows the low-angle X-ray diffraction (XRD) patterns of SBA-15 silica and OMC. The peaks between $\mathrm{O}$ and $4 \mathrm{O} 2 \mathrm{~h}$ in Fig. 4 are indicative of the regular mesoporous structure of the host (SBA-15) and the replica (OMC) materials. As shown in Fig. 4 the low-angle diffraction peak of the SBA-15 is centered at $202 \mathrm{~h}$, which corresponds to a d interplanar spacing of $4.4 \mathrm{~nm}$ (calculated using Bragg equation). The low-angle diffraction peak of the OMC is centered at $2.50 \mathrm{2h}$, corresponding to a d spacing of $3.5 \mathrm{~nm}$. The decrease in the d spacing value (Table 1) and shift in the position of the diffraction peak (Fig. 4) of the OMC relative to those of the SBA-15 indicate that the silica/carbon composite most likely underwent structural shrinkage due to carbonization at $800 \mathrm{oC}$ and during template removal [26]. The unit cell parameters of the SBA-15 and the OMC were calculated using the formula $\mathrm{a}=\left(2 / 3^{1 / 2}\right) * \mathrm{~d}_{100}$ and were determined to be 5.08 and $4.04 \mathrm{~nm}$, respectively, demonstrating a decrease in the distance between the pore centers of the OMC structure compared to that in the host silica [27].

Nitrogen adsorption/desorption analysis further confirmed the ordered structure of OMC. SBA-15 was also investigated for comparison. As shown in Fig. 5a, the nitrogen adsorption/desorption isotherms of SBA-15 and OMC are typical type IV isotherms, with hysteresis loops at relative pressures $\mathrm{p} / \mathrm{p}_{\mathrm{O}} 0.45^{-0.6}$ of for SBA-15 and $0.45^{-0.99}$ for the OMC [28]. The hysteresis loop of the OMC (H1 type) is a steep and narrow loop that consists of nearly parallel adsorption and desorption branches, indicative of an adsorbent that has a uniform pore size distribution over a narrow range [29]. The BET surface areas of SBA-15 and OMC were determined to be 878 and $1,783 \mathrm{~m}^{2} / \mathrm{g}$, respectively (Table 1). Other OMC materials obtainned via CVD using SBA-15 silica as the template and acetonitrile, styrene and benzene as carbon sources showed smaller surface areas with various pore sizes $[21,22,30]$. The mesoporous surface areas of SBA-15 and OMC were calculated from the BJH adsorption data (Table 1). The mesoporous surface area of OMC was significantly higher than its BET surface area. The over-estimation of the mesoporous surface area of OMC may arise from using the BJH method [31]. The pore size distributions of SBA-15 and OMC are shown in Fig. 5b. While the mesopore size of SBA-15 was centered at $3.2 \mathrm{~nm}$, OMC exhibited a bimodal-like pore structure with primary and secondary mesopores centered at 2.8 and $2.2 \mathrm{~nm}$, respectively (Table 2). Primary and secondary mesopores occupied 69 and $31 \%$, respectively, of the total mesoporous surface area of OMC. The pore wall thickness of the SBA-15 and OMC were calculated according to the equation $t=a-d B J H$, where the first term is the unit cell parameter and the second term is the primary mesopore size of the material obtained from BJH adsorption data (Table 1) [32]. 


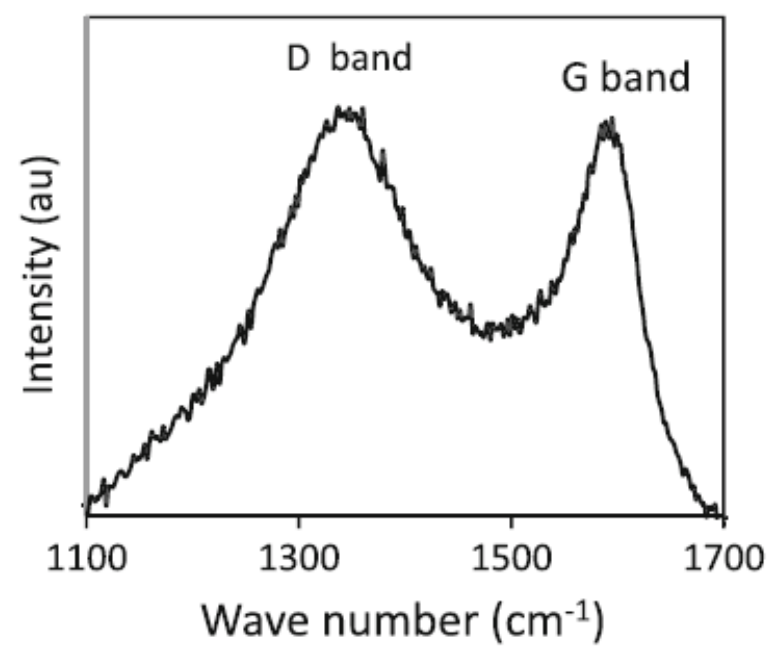

Fig. 3 Raman spectrum of OMC
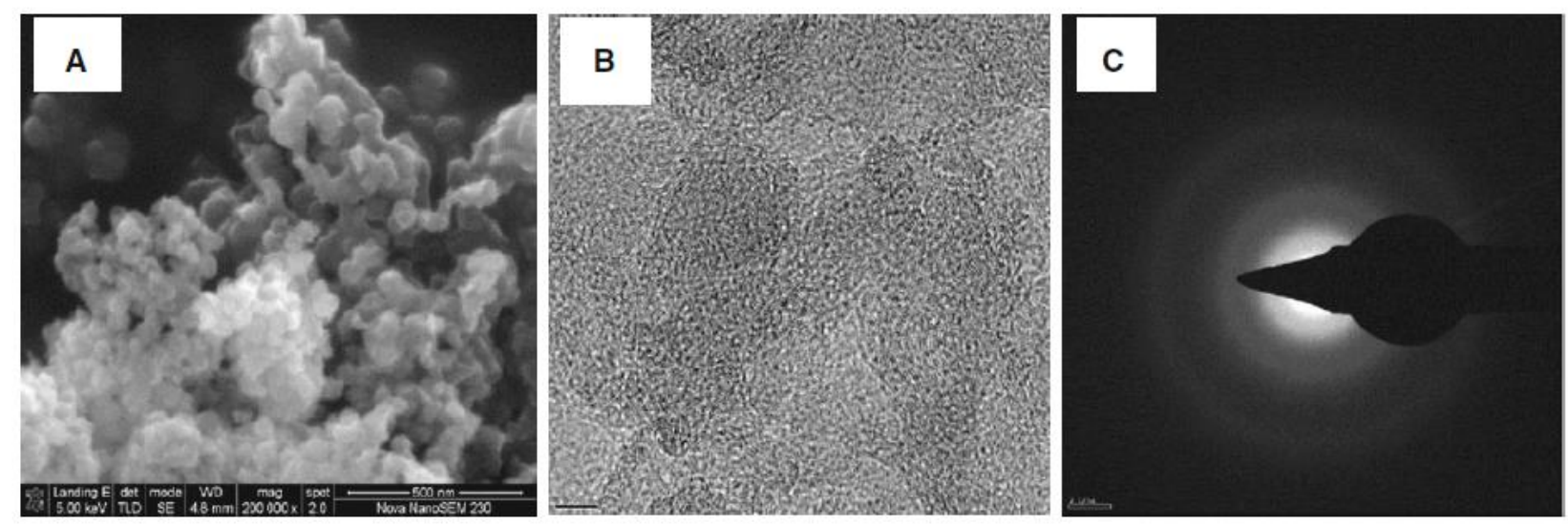

Fig. 2 SEM (a), HRTEM (b) images and SAED pattern (c) of OMC

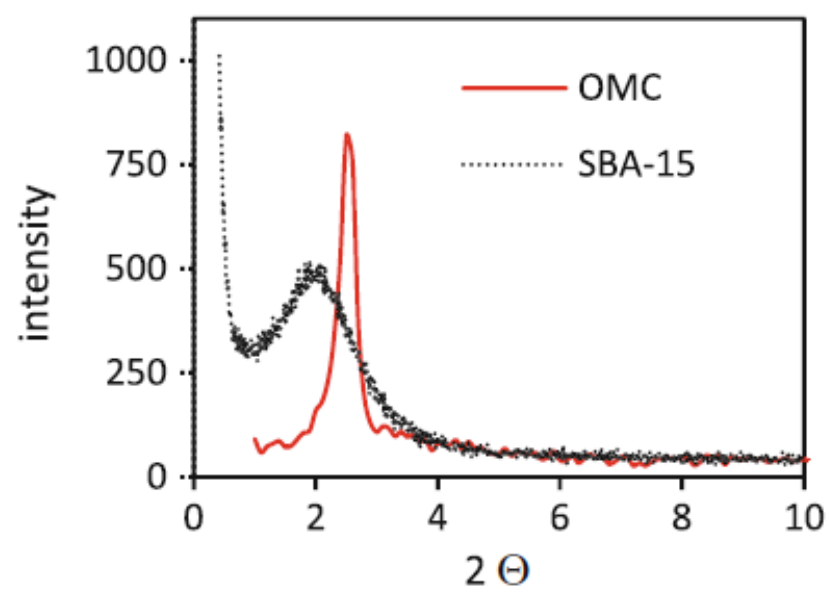

Fig. 4 The low-angle XRD patterns of SBA-15 and OMC

http://repository.uwc.ac.za 
The nitrogen adsorption/desorption isotherm and pore size distribution of the AC are shown in Fig. 6. The slightly increasing trend of the isotherm and its hysteresis loop indicates that the AC had mesopores (Fig. 6a). The AC had a BET surface area of $551 \mathrm{~m}^{2} / \mathrm{g}$ and a mixed micro- and mesoporous structure. The mesopores of the AC exhibited a wide size range, with two peaks centered at 2 and $4 \mathrm{~nm}$ (Fig. 6b). The surface areas under the peaks of 2 and $4 \mathrm{~nm}$ were 130 and $155 \mathrm{~m}^{2} / \mathrm{g}$, respectively. The mesoporous area of AC was approximately more than twice as large as its microporous area (Table 1).

\subsection{Adsorption \\ 3.2.1 Effect of $\mathbf{p H}$ on adsorption}

The $\mathrm{pH}$ of dye solutions may or may not affect their adsorption [33]. To determine the role of $\mathrm{pH}$ in the adsorption of $\mathrm{AO}, \mathrm{MB}$, or $\mathrm{RB}$ on $\mathrm{OMC}$ and $\mathrm{AC}$, experiments were carried out using $100 \mathrm{mg} / \mathrm{L}$ dye solutions with different $\mathrm{pH}$ values. The results are shown in Fig. 7. In the case of the $\mathrm{AO} 8$ adsorption on $\mathrm{OMC}$, the percent removal of $\mathrm{AO} 8$ was maximum at $\mathrm{pH}$ 2 , at which the surface became positively charged and the affinity between the surface and anionic AO8 was maximum (Fig. 7a). When the $\mathrm{pH}$ increased from 2 to 5, the adsorption isotherm decreased steadily because the concentration of $\mathrm{OH}^{-}$ions present in the solution increased, resulting in a change towards negative charge on the adsorbent surface. The percent removal of AO8 remained nearly constant between $\mathrm{pH} 5$ and $\mathrm{pH} 8$, indicating electrostatic repulsion between $\mathrm{AO} 8$ and the OMC surface. In Fig. 7b, the percent removal of $\mathrm{MB}$ on $\mathrm{OMC}$ was the lowest at $\mathrm{pH} 2$, indicating repulsion between the positively charged adsorbent surface and the cationic dye. The removal of MB from the solution showed a fast increase between $\mathrm{pH} 2$ and 6 due to the increasing attraction between the cationic MB molecules and the adsorbent surface. Above $\mathrm{pH} \mathrm{6}$, the percent removal slowly increased and reached $100 \%$ at $\mathrm{pH}$ 12. Meanwhile, the percent removal of $\mathrm{RB}$ was not affected considerably by increasing $\mathrm{pH}$ (Fig. $7 \mathrm{c}$ ). Because RB is a basic dye, a higher percent removal was expected at higher $\mathrm{pH}$ values. Therefore, it may be reasonable to believe that a size exclusion effect dominated the adsorption of $\mathrm{RB}$, which is a larger molecule than MB. The adsorption of $\mathrm{AO}, \mathrm{MB}$, and $\mathrm{RB}$ on $\mathrm{AC}$ followed the same $\mathrm{pH}$ trend observed for the OMC. Subsequent adsorption equilibrium studies were performed at the natural $\mathrm{pH}$ levels of each dye, which were measured to be 6.2, 6.0, and 7.5 for AO8, MB, and RB, respectively, in $100 \mathrm{mg} / \mathrm{L}$ solutions.

\subsubsection{Adsorption isotherms}

An adsorption isotherm shows the distribution of adsorbed dye molecules between solid and liquid phases at equilibrium [11]. Isotherms obtained from the adsorption of acid orange 8 (AO8), methylene blue (MB) and rhodamine $\mathrm{B}(\mathrm{RB})$ on $\mathrm{OMC}$ and $\mathrm{AC}$, respectively, are plotted in Fig. 7 as dots. In general, the trends for adsorption can be correlated to the surface area of each adsorbent: OMC has a high surface area mainly composed of ordered mesopores, which is suitable for accommodating large dye molecules. In contrast to $\mathrm{OMC}, \mathrm{AC}$ has a smaller surface area composed of mixed micro- and mesopores, resulting in lower dye adsorption compared to that of OMC.

The monolayer or maximum adsorption capacities of $\mathrm{OMC}$ and $\mathrm{AC}$ for the investigated dyes were determined by applying the Langmuir model to the experimental data (Fig. 8). The Langmuir equation and its linear form are as follows (Eq. 2a, 2b) [34].

\section{http://repository.uwc.ac.za}




$$
\begin{aligned}
& \mathrm{Qe}=\mathrm{Q}_{\mathrm{o}} * \mathrm{~b} * \mathrm{C}_{\mathrm{e}} /\left(1+\mathrm{b} * \mathrm{C}_{\mathrm{e}}\right) \\
& \left(\mathrm{C}_{\mathrm{e}} / \mathrm{Q}_{\mathrm{e}}\right)=\left(\mathrm{C}_{\mathrm{e}} / \mathrm{Q}_{\mathrm{o}}\right)+\left(1 / \mathrm{bQ}_{\mathrm{o}}\right)
\end{aligned}
$$

In Eq. $2 b, \mathrm{C}_{e}$ and $\mathrm{Qe}_{\mathrm{e}}$ are the liquid and solid equilibrium concentration of the dye, $\mathrm{Q}_{\mathrm{o}}$ and $\mathrm{b}$ are Langmuir constants related to the maximum adsorption capacity $(\mathrm{mg} / \mathrm{g})$ and affinity of adsorption between the dyes and the carbon adsorbent $(\mathrm{L} / \mathrm{mg})$, respectively. As shown in Fig. 8, the shapes of the Langmuir isotherms were of the L2-type according to the classification established by Giles and Smith. L-type curves or Langmuir isotherms usually imply the flat adsorption of molecules on an adsorbent surface [35, 36]. The initial part of the isotherm describing $\mathrm{MB}$ adsorption on $\mathrm{OMC}$ was nearly vertical, indicating a very high affinity between the dye and the adsorbent.

The Langmuir adsorption capacities of $\mathrm{AO} 8$ on $\mathrm{OMC}$ and $\mathrm{AC}$ were determined to be 222 and $141 \mathrm{mg} / \mathrm{g}$, respectively (Table 2). The maximum adsorption capacities of MB on OMC and $\mathrm{AC}$ were determined to be 833 and $313 \mathrm{mg} / \mathrm{g}$, respectively. Finally, the adsorption capacities of RB on OMC and AC were determined to be 233 and $185 \mathrm{mg} / \mathrm{g}$, respectively. Regarding the adsorption of $\mathrm{AO8}, \mathrm{MB}$ and $\mathrm{RB}$, the highest adsorption was observed with $\mathrm{MB}$, which is smaller than $\left(1.52^{*} 0.69 * 0.50 \mathrm{~nm}^{3}\right) \mathrm{AO} 8\left(1.50^{*} 0.88^{*} 0.46 \mathrm{~nm}^{3}\right)$ and the largest molecule $\mathrm{RB}\left(1.61^{*} 1.29^{*} 0.71 \mathrm{~nm}^{3}\right)$. Thus, $\mathrm{MB}$ was adsorbed more readily, compared to the larger molecules AO8 and RB. The molecular size of a dye molecule has been reported to have an important impact on adsorption phenomena [31]. 
Table 1 Pore sizes and surface areas of SBA-15, OMC, and AC

\begin{tabular}{|c|c|c|c|c|c|c|c|}
\hline & $\mathrm{d}_{100}^{\mathrm{a}}(\mathrm{nm})$ & $a^{b}(n m)$ & $\mathrm{S}_{\mathrm{BET}}\left(\mathrm{m}^{2} / \mathrm{g}\right)$ & $\mathrm{d}_{\mathrm{BJH}}^{\mathrm{c}}(\mathrm{nm})$ & $\mathrm{t}_{\mathrm{wall}}^{\mathrm{d}}(\mathrm{nm})$ & $\mathrm{S}_{\text {micro }}\left(\mathrm{m}^{2} / \mathrm{g}\right)$ & $\mathrm{S}_{\text {mesd }}\left(\mathrm{m}^{2} / \mathrm{g}\right)$ \\
\hline $\mathrm{OMC}$ & 3.5 & 4.04 & 1,783 & $2.2-2.8$ & 0.7 & - & 2,088 \\
\hline SBA-15 & 4.4 & 5.08 & 878 & 3.2 & 1.2 & - & 671 \\
\hline $\mathrm{AC}$ & & & 551 & $0-10$ & & 168 & 383 \\
\hline
\end{tabular}

a Interplanar spacing

${ }^{\mathrm{b}}$ Unit cell parameter $\left(\mathrm{a}=\left(2 / 3^{1 / 2}\right)^{*} \mathrm{~d}_{100}\right)$

c Pore size calculated from BJH adsorption data

${ }^{d}$ Pore wall thickness $\left(d_{t}=a-d_{B J H}\right)$

Fig. $5 \mathrm{~N}_{2}$ adsorption/ desorption isotherms (a) and pore size distributions (b) of SBA-15 and OMC
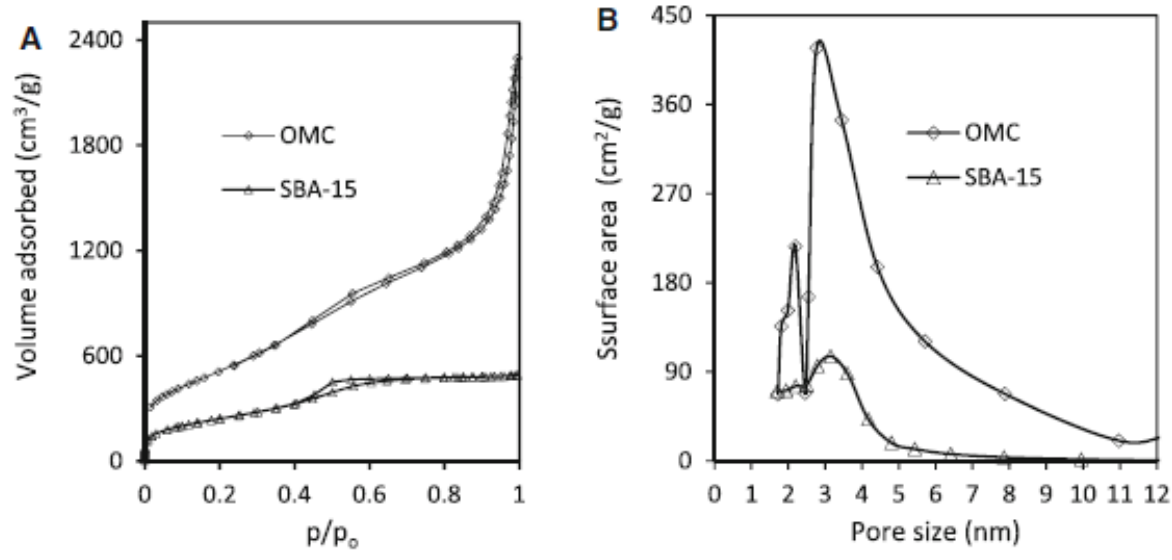

Table 2 Langmuir constants in the adsorption of AO8, MB, and AC on OMC and AC

\begin{tabular}{|c|c|c|c|c|c|c|c|}
\hline \multirow[t]{2}{*}{ Model } & \multirow{2}{*}{$\begin{array}{l}\text { Model coefficients and } \\
\text { correlation factor }\end{array}$} & \multicolumn{2}{|l|}{ AO8 } & \multicolumn{2}{|l|}{ MB } & \multicolumn{2}{|l|}{ RB } \\
\hline & & $\mathrm{OMC}$ & $\mathrm{AC}$ & $\mathrm{OMC}$ & $\mathrm{AC}$ & $\mathrm{OMC}$ & $\mathrm{AC}$ \\
\hline \multirow[t]{3}{*}{ Langmuir } & $\mathrm{Q}_{\mathrm{o}}(\mathrm{mg} / \mathrm{g})$ & 222 & 141 & 833 & 313 & 233 & 185 \\
\hline & b (L/mg) & 0.04 & 0.14 & 0.39 & 0.14 & 0.21 & 0.31 \\
\hline & $\mathrm{R}^{2}$ & 0.9860 & 0.9997 & 0.9871 & 0.9943 & 0.9824 & 0.9968 \\
\hline
\end{tabular}

Fig. $6 \mathrm{~N}_{2}$ adsorption/ desorption isotherm (a) and Pore size distribution (b) of $\mathrm{AC}$

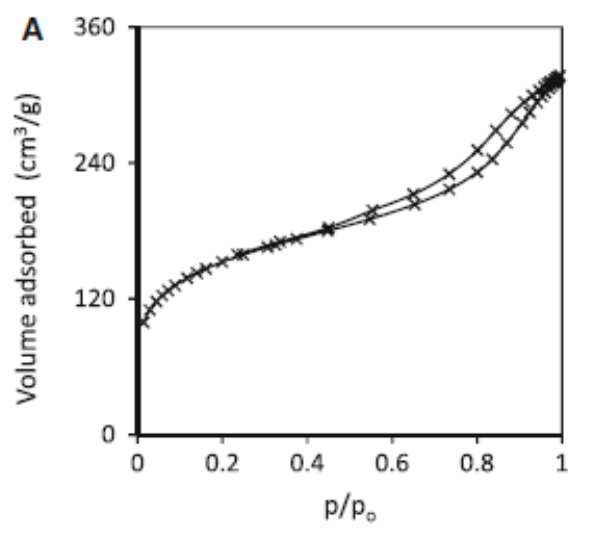



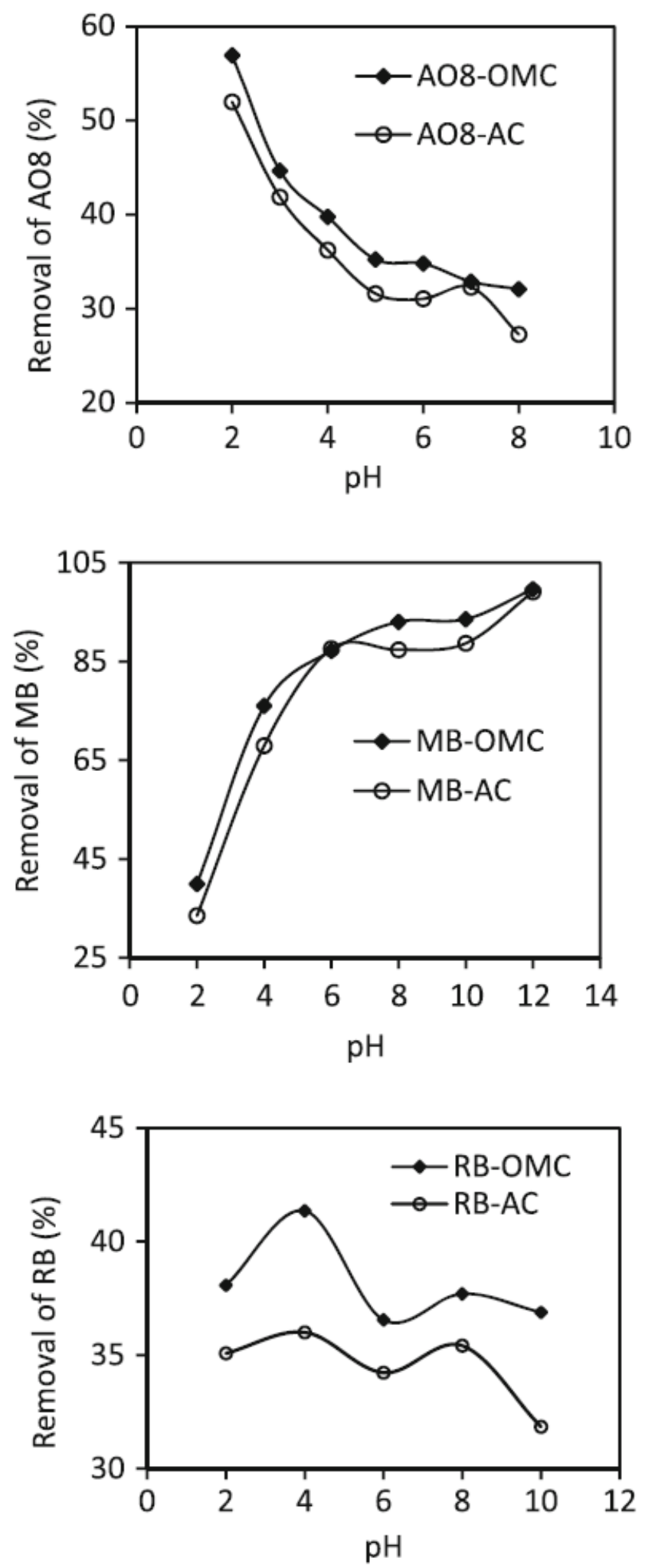

Fig. 7 Effect of $\mathrm{pH}$ on adsorption of dyes

http://repository.uwc.ac.za 

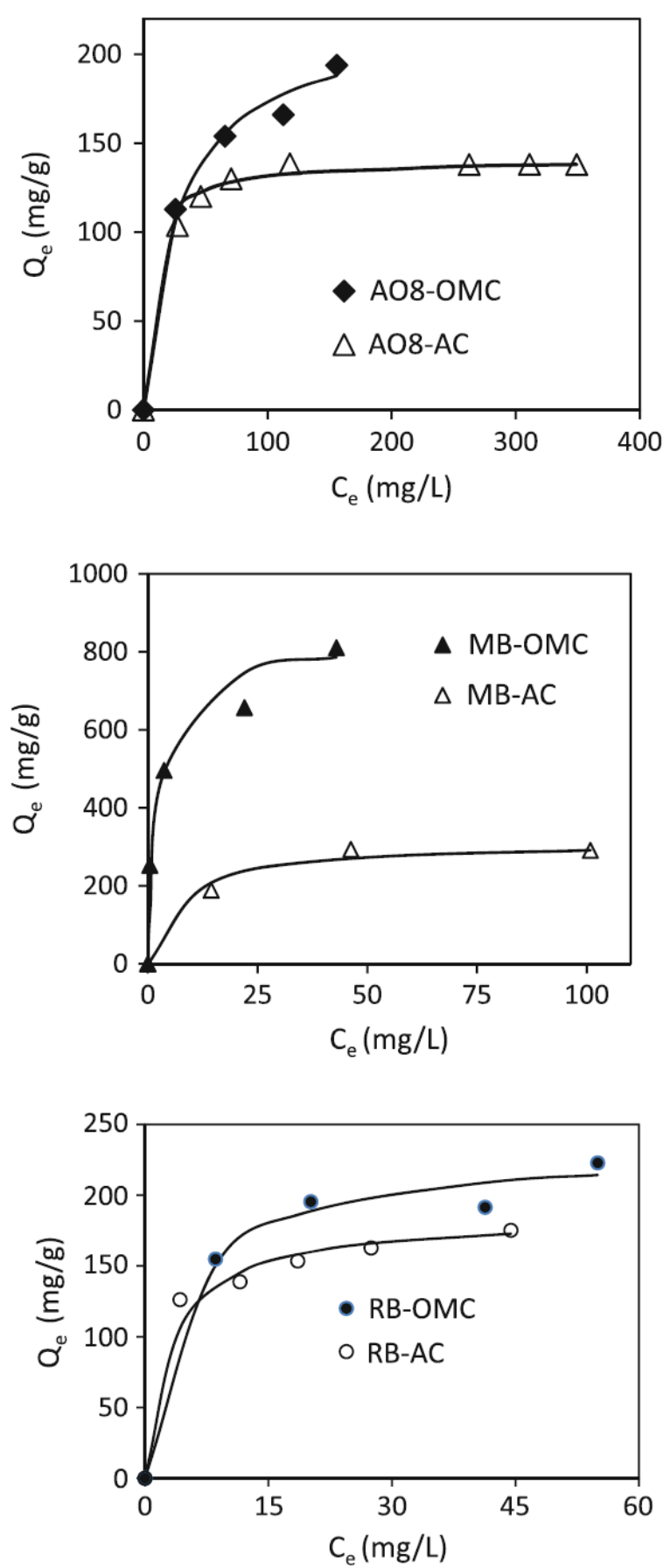

Fig. 8 Langmuir and experimental adsorption isotherms of dyes onto $\mathrm{OMC}$ and $\mathrm{AC}$ (lines model; dots experimental)

In the present study, the very high MB adsorption observed in the case of OMC may be related to the similarity between the molecular size of MB and the mesopore size of OMC, as well as the maximum electrostatic attraction between MB and OMC at pH 7.5 (Fig. 6b) and the van der Waals interactions established between hexagonally structured graphitic carbon atoms present in the OMC and aromatic rings in the structure of ionic dye [37]. As shown in Table 2, the adsorption capacities of AO8 and RB on OMC were 222 and $233 \mathrm{mg} / \mathrm{g}$, respectively, although one can expect higher AO8 adsorption than $\mathrm{RB}$ adsorption due to the smaller molecular size of AO8 compared to that of RB. The nearly similar adsorption

\section{http://repository.uwc.ac.za}


capacities for $\mathrm{AO} 8$ and $\mathrm{RB}$ on $\mathrm{OMC}$ can be correlated with the establishment of electrostatic repulsion between $\mathrm{AO} 8$ and the surface of OMC at $\mathrm{pH} 6.2$ (Fig. 7a) and electrostatic attraction between the cationic $\mathrm{RB}$ and the surface of $\mathrm{OMC}$ at $\mathrm{pH} 7.5$ (Fig. $7 \mathrm{c}$ ), which may have contributed to the considerable adsorption of the larger RB molecules.

The adsorption of AO8, MB, or RB on AC followed the order MB Г RB Г AO8, as in the adsorption of the same dyes on OMC (Table 2). MB was the most highly adsorbed dye on $\mathrm{AC}(313 \mathrm{mg} / \mathrm{g})$ because of its smaller size compared to AO8 and RB, as well as the observed attraction between $\mathrm{MB}$ molecules and the surface of $\mathrm{AC}$ at the adsorption $\mathrm{pH}$ of 7.5 (Fig. 7a). The adsorption of the larger RB molecules $(185 \mathrm{mg} / \mathrm{g}$ ) was higher than that of the smaller AO8 molecules $(141 \mathrm{mg} / \mathrm{g}$ ). This was due both to the maximum electrostatic attraction between $\mathrm{RB}$ molecules and the $\mathrm{AC}$ surface at $\mathrm{pH} 7.5$ (Fig. $7 \mathrm{c}$ ) and the mesoporous structure of $\mathrm{AC}$, which did not restrict the penetration of large $\mathrm{RB}$ molecules. In Table 2, all of the correlation coefficients $\left(\mathrm{R}^{2}\right)$ related to dye adsorption on $\mathrm{OMC}$ and $\mathrm{AC}$ are higher than 0.98, indicating that the Langmuir model fit all of the experimental equilibrium data well.

\subsubsection{Surface coverage}

The surface coverage of each dye can be estimated using the saturated surface concentration of the dye $(\mathrm{mol} / \mathrm{g}$ ), Avogadro's number (molecules $/ \mathrm{mol}$ ) and the molecular surface area of the dye (length*width- $\left.{ }^{2}\right)$. The surface coverage values $\left(\mathrm{m}^{2} / \mathrm{g}\right)$ of the primary and secondary mesoporous areas of the OMC can be compared, thus providing information on the pore utilization. However, in the nitrogen adsorption/desorption analysis, the BJH method overestimated the mesoporous surface area of the OMC. Therefore, an assumption was necessary to express the real primary and secondary mesoporous surface areas of the OMC. Specifically, the BET surface area of the OMC was multiplied by the percent values (69 and $31 \%$ ) calculated from the BJH analysis of the primary and secondary mesoporous areas of the OMC. Thus, the primary and secondary mesoporous areas of the OMC were estimated to be 1,230 and $553 \mathrm{~m}^{2} / \mathrm{g}$, respectively. Table 3 shows the surface coverage of AO8, MB and RB on OMC and AC. The surface coverage of MB was $1,600 \mathrm{~m}^{2} / \mathrm{g}$, as shown in Table 3 . This value is less than BET surface area of the OMC, indicating monolayer adsorption of MB molecules onto the adsorbent. It is most likely that $\mathrm{MB}$, due to its ability to access $1.5 \mathrm{~nm}$ pores, was adsorbed both in the primary and secondary mesopores of the OMC [38]. The large RB molecule can access pores measuring $2.6 \mathrm{~nm}$ or larger, which were located in the primary mesoporous area of the OMC, resulting in a surface coverage value of $581 \mathrm{~m}^{2} / \mathrm{g}$ [38]. Because the molecular size of $\mathrm{AO8}$ is between that of $\mathrm{MB}$ and $\mathrm{RB}$, it was most likely adsorbed on the primary mesoporous area of the OMC, covering an area of $423 \mathrm{~m}^{2} / \mathrm{g}$, a value which is less than the coverage determined for RB. The surface coverage of MB molecules on AC $\left(575 \mathrm{~m}^{2} / \mathrm{g}\right.$ ) was slightly larger than its BET surface area $\left(551 \mathrm{~m}^{2} / \mathrm{g}\right)$, indicating multilayer adsoption occurred in some pores. AO8 and RB occupied 301 and $457 \mathrm{~m}^{2} / \mathrm{g}$, respectively, on AC. The coverage of AC pores by the investigated dyes could not be investigated in detail due to the mixed micro- and meso structure of this material.

In the literature, OMCs synthesized using a SBA-15 silica template and sucrose as the carbon source have been used in the adsorption of methylene blue and neutral red, direct yellow 12 and remazol red $3 \mathrm{BS}$ from the aqueous

\section{http://repository.uwc.ac.za}


phase [31, 39, 40]. These studies have demonstrated the relationship between the pore size of adsorbents and the molecular size of dyes in adsorption, as indicated in this study. The AC used in this work showed a higher AO8 capacity than that of lower-surface-area activated carbons prepared from guava seed and the husk of mango seed [9, 10]. The MB adsorption capacity of the AC used in this study was compared to that of other ACs obtained from different sources, and $\mathrm{MB}$ adsorption capacities that are lower or higher than that of the AC used in this work were found [11, 41, 42]. AC sourced from SAARChem showed a higher RB adsorption capacity compared to that of other ACs obtained using agricultural by products and sago waste $[43,44]$.

\section{Conclusions}

Ordered mesoporous carbon was successfully synthesized using a chemical vapor deposition (CVD) technique and liquid petroleum gas (LPG) as the carbon source. An SBA15 silica template was penetrated with the carbon precursor LPG, which was carbonized at $800 \mathrm{oC}$ to form an ordered graphitic carbon structure in the SBA-15 template. Once the silica template was removed by $\mathrm{NaOH}$ etching, the obtained OMC exhibited an ordered bimodal mesoporous structure with pores centered at 2.8 and $2.2 \mathrm{~nm}$ and a large ordered mesoporous surface area. The CVD technique using liquid petroleum gas (LPG) was shown to be a rapid and simple method for preparing graphitic OMC materials, as was confirmed by Raman and HRTEM analyses.

The OMC was utilized in the removal of AO8, MB and RB from aqueous solution. The OMC showed a higher adsorption capacity $(833 \mathrm{mg} / \mathrm{g}$ ) for $\mathrm{MB}$ compared to the capacities for AO8 (222 mg/g) and RB (233 mg/g) adsorption. The very high MB adsorption was ascribed to the similarity between the mesopore size of the OMC and the molecular size of $\mathrm{MB}$, as well as the high mesoporous surface area of the $\mathrm{OMC}$ and the electrostatic attraction between the OMC and MB. The OMC used in this study was determined to be an excellent adsorbent for the removal of MB from wastewater. The adsorption capacities of $\mathrm{AO8}, \mathrm{MB}$ and $\mathrm{RB}$ on $\mathrm{AC}$ were determined to be 141, 313, and 185, respectively, demonstrating the relative disadvantage of $\mathrm{AC}$ in the adsorption of large dye molecules.

\section{Table 3 Surface coverage of $\mathrm{AO}, \mathrm{MB}$, and $\mathrm{AC}$ on $\mathrm{OMC}$ and $\mathrm{AC}$}

\begin{tabular}{|c|c|c|c|c|c|c|}
\hline & \multicolumn{2}{|l|}{ AO8 } & \multicolumn{2}{|l|}{$\mathrm{MB}$} & \multicolumn{2}{|l|}{$\mathrm{RB}$} \\
\hline & $\mathrm{OMC}$ & $\mathrm{AC}$ & $\mathrm{OMC}$ & $\mathrm{AC}$ & $\mathrm{OMC}$ & $\mathrm{AC}$ \\
\hline Surface coverage $\left(\mathrm{m}^{2} / \mathrm{g}\right)$ & 423 & 301 & 1,600 & 575 & 581 & 457 \\
\hline
\end{tabular}

Acknowledgments The authors would like to thank Dr. Armag an Kinal for calculating the molecular dimensions of acid orange 8, methylene blue, and rhodamine $\mathrm{B}$ and the Water Research Commission (WRC) and National Research Foundation of South Africa (NRF) for funding this study. 


\section{References}

1. T. Robinson, G. McMullan, R. Marchant, P. Nigam, Bioresour Technol 77, 247 (2001)

2. C.I. Pearce, J.R. Lloyd, J.T. Guthrie, Dyes Pigm 58, 179 (2003)

3. G. Crini, Bioresour Technol 97, 1061 (2006)

4. Karadag, Dyes Pigm 74, 659 (2007)

5. R. Malik, D.S. Ramteke, S.R. Wate, Waste Manag. 27, 1129 (2007)

6. V.K. Gupta, Suhas, J Environ Manag 90, 2313 (2009)

7. R. Malarvizhi, Y.S. Ho, Desalination 264, 97 (2010)

8. F.C. Wu, R.L. Tseng, R.S. Juang, J. Environ. Sci. Health A 34(9), 1753 (1999)

9. M.P. Elizalde-Gonzalez, L.E. Garcia-Diaz, Chem Eng J 163, 55 (2010)

10. M.M. Davila-Jimenez, M.P. Elizalde-Gonzalez, V. Hernandez-Montoya, Bioresour Technol 100, 6199 (2009)

11.B.H. Hameed, A.L. Ahmad, K.N.A. Latiff, Dyes Pigm 75, 143 (2007)

12. J. Avom, J.K. Mbadcam, C. Noubactep, P. Germain, Carbon 35(3), 365 (1997)

13. J.H. Huang, K.L. Huang, S.Q. Liu, A.T. Wang, C. Yan, Colloids and Surfaces A: Physicochem. Eng. Asp. 330, 55 (2008)

14. E. Lorenc-Grabowska, G. Gryglewicz, Dyes Pigm 74, 34 (2007)

15. H. Tamai, T. Kakii, Y. Hirota, T. Kumamoto, H. Yasuda, Chem Mater 8, 454 (1996)

16. H. Darmstadt, C. Roy, S. Kaliaguine, S.H. Joo, R. Ryoo, Micro Mesoporous Mater. 60, 139 (2003)

17.Vinu, T. Moria, K. Ariga, Sci Technol Adv Mater 7, 753 (2006)

18. F. Kleitz, S.H. Choi, R. Ryoo, Chem. Commun. 2136 (2003)

19. J. Lee, J. Kim, T. Hyeon, Adv Mater 18, 2073 (2006)

20. P. Ndungu, Z.G. Godongwana, L.F. Petrik, A. Nechaev, S. Liao, V. Linkov, Micropor. Mesopor. Mater. 116, 593 (2008)

21. Xia, Z. Yang, R. Mokaya, Chem Mater 18, 140 (2006)

22. Xia, R. Mokaya, Adv Mater 16(17), 1553 (2004)

23. Y. Shao, L.F. Molnar, Y. Jung, J. Kussmann, C. Ochsenfeld, S.T. Brown, A.T.B. Gilbert, L.V. Slipchenko, S.V. Levchenko, D.P. O’Neill, R.A. DiStasio Jr., R.C. Lochan, T. Wang, G.J.O. Beran, N.A. Besley, J.M. Herbert, C.Y. Lin, T. Van Voorhis, S.H. Chien, Sodt, R.P. Steele, V.A. Rassolov, P.E. Maslen, P.P. Korambath, R.D. Adamson, B. Austin, J. Baker, E.F.C. Byrd, H. Dachsel, R.J. Doerksen, A. Dreuw, B.D. Dunietz, A.D. Dutoi, T.R. Furlani, S.R. Gwaltney, A. Heyden, S. Hirata, C-P. Hsu, G. Kedziora, R.Z. Khalliulin, P. Klunzinger, A.M. Lee, M.S. Lee, W.Z. Liang, I. Lotan, N. Nair, B. Peters, E.I. Proynov, P.A. Pieniazek, Y.M. Rhee, J. Ritchie, E. Rosta, C.D. Sherrill, A.C. Simmonett, J.E. Subotnik, H.L. Woodcock III, W. Zhang, A.T. Bell, A.K. Chakraborty, D.M. Chipman, F.J. Keil, A. Warshel, W.J. Hehre, H.F. Schaefer, J. Kong, A.I. Krylov, P.M.W. Gill and M. HeadGordon, Phys. Chem. Chem. Phys., 8, 3172 (2006)

24. J. Parmentier, S. Saadhallah, M. Reda, P. Gibot, M. Roux, L. Vidal, C. Vix-Guterl, J. Patarin, J Phys Chem Solids 65, 139 (2004)

25. O. Beyssac, J.N. Rouzaud, B. Goffé, F. Brunet, C. Chopin, Contrib. Mineral. Petrol. 143, 19 (2002)

26. C.M. Yang, C.C. Weidenthaler, B. Spliethoff, M. Mayanna, F. Schü th, Chem Mater 17, 355 (2005)

27. M. Kruk, M. Jaroniec, Chem Mater 11, 492 (1999)

28. K.S.W. Sing, D.H. Everett, R.A.W. Haul, L. Moscou, R.A. Pierotti, J. Rouquerol, T. Siemieniewska, Pure App. Chem. 57(4), 603 (1985)

29. J. Rouquerol, F. Rouquerol, K.S.W. Sing, Adsorption by powders and porous solids (Academic Press, London, 1998)

30. $\quad$ F. Su, J. Zeng, X. Bao, Y. Yu, J.Y. Lee, X.S. Zhao, Chem Mater 17, 3960 (2005)

\section{http://repository.uwc.ac.za}


31. X. Yuan, S.P. Zhuo, W. Xing, H.Y. Cui, X.D. Dai, X.M. Liu, Z.F. Yan, J Colloid Interface Sci 310, 83 (2007)

32. $\quad$ S.H. Liu, S.C. Chen, J Solid State Chem 184, 2420 (2011)

33. $\quad$ S.K. Das, J. Bhowal, A.R. Das, A.K. Guha, Langmuir 22, 7265 (2006)

34. Ata, O.O. Nalcaci, B. Ovez, Algal Res. 1, 194 (2012)

35. C.H. Giles, D. Smith, A. Hutson, J Coll Inter. Sci. 47(3), 755 (1974)

36. C.H. Giles, T.H. MacEwan, S.N. Nakhwa, D. Smith, J Chem Soc 3, 3973 (1960)

37. Fugetsu, S. Satoh, T. Shiba, T. Mizutani, Y.B. Lin, N. Terui, Y. Nodasaka, K. Sasa, K. Shimizu, T. Akasaka, M. Shindoh, K.I. Shibata, A. Yokoyama, M. Mori, K. Tanaka, Y. Sato, K. Tohji, S. Tanaka, N. Nishi, F. Watari, Environ Sci Technol 38, 6890 (2004)

38. G.M. Walker, L.R. Weatherley, Chem Eng J 83, 201 (2001)

39. F. Liu, J. Wang, L. Li, Y. Shao, Z. Xu, S. Zheng, J Chem Eng Data 54, 3043 (2009)

40. D.D. Asouhidou, K.S. Triantafyllidis, N.K. Lazaridis, K.A. Matis, S.S. Kim, T.J. Pinnavaia, Microporous Mesoporous Mater 117, 257 (2009)

41. B.H. Hameed, A.T.M. Din, A.L. Ahmad, J. Hazard. Mater. 141, 819 (2007)

42. M. Belhachemi, F. Addoun, Appl. Water Sci. 1, 111 (2011)

43. H.M.H. Gad, A.A. El-Sayed, J. Hazard. Mater. 168, 1070 (2009)

44. K. Kadirvelu, C. Karthika, N. Vennilamani, S. Pattabhi, Chemosphere 60, 1009 (2005) 